Aydın, B. / Sosyal Bilimler Araştırmaları Dergisi. 2, (2006): 19-32

\title{
Öğretmenlerin Kendi Sınıf Disiplin Sistemlerini Oluşturması
}

\section{Bahri Aydın ${ }^{a}$}

\begin{abstract}
Özet
Sınıfta disiplini sağlama öğretmenlerin önemli rollerinden biridir. Öğretmenler, öğrencilerin psikolojik ve fiziksel sağlığına dikkat ederek sınıfta disiplini sağlamalıdır. Sınıfta disiplini sağlamak için birçok model geliştirilmiştir. Öğretmenler, disiplini sağlamada bu modellerden yararlanabilirler. Ancak, öğretmenler bir ders için yıllık veya günlük olarak bir plana gereksinim duyuyorlarsa sinıfta disiplini sağlarken de yeni bir döneme başlamadan önce disiplin sistemlerini oluşturmalıdırlar. Çünkü sınıfta disiplin, belirli bir sistem uygulanabilirse etkili şekilde sağlanabilir. Bu çalışmada da öğretmenlere, disiplin sistemini oluşturmada yardımcı olacak ölçütler verilmeye çalışılmıştır.
\end{abstract}

Anahtar sözcükler: Disiplin, disiplin sistemi

\begin{abstract}
Maintaining discipline in the classroom is one of the most important roles of a teacher. Teachers should provide classroom discipline by paying attention to student's psychological and physical health. Many models have been developed to provide discipline in the classroom. Teacher might utilize these models to maintain discipline. However, teachers should secure their discipline systems before they start new term as they need a daily and an annual plan for a lesson. The reason behind this is that classroom discipline can be kept if it is practiced in a definite system. This study aims to give teachers the criteria to form their disciplinary systmes.
\end{abstract}

Key words:Disciplin,disciplinary system

${ }^{a}$ Yrd. Doç. Dr. Abant İzzet Baysal Üniversitesi, Eğitim Fakültesi, Bolu, bahriaydin@hotmail.com 


\section{Giriş}

Disiplin kavramı itici ve soğuk olarak düşünülebilir. Bunun nedeni, disiplinin ceza, dayak, disiplin kurulu gibi kavramlarla yan yana fazla gelmesi olabilir. Gordon (2000) disiplinin anlamı, sınıfa yansıyan olumsuz öğretmen davranışları ve bu davranışların öğrenci üzerindeki etkileri üzerinde durmaktadır. Gordon'a göre disiplinin iki anlamı vardır. Birincisinin amacı denetleme iken ikincisinin amacı öğretme ve eğitmedir. Birincisi ile kullanılan kavramlar; düzeltmek, yönlendirmek, hizaya sokmak, sıkı denetim altına almak, sinırlamak, bastırmak, durdurmak, gem vurmak, susturmak, zorlamak, engellemek, cezalandırmak, dayakla adam etmek, şiddetle azarlamak, ayıplamak, eleştirmek, başkalarına ibret olsun diye cezalandırmak....vb. iken ikincisi ile birlikte kullanılan kavramlar bilgi vermek, aydınlatmak, ahlakını düzeltmek, bilgilendirmek, yetiştirmek, önderlik etmek..vb'dir. Öğretmen bu iki yaklaşımdan hangisini benimseniyorsa davranışları da ona göre şekillenebilir.

"Denetleme" anlayışına sahip olan öğretmenin davranışları sınıflara; sarsma, itekleme, tekmeleme, firlatma, tuvalete gitmesine izin vermeme, arkadaşlarının çocuğa kötü davranmasına göz yumma, onur kırıcı sözler söyleme, alay etme, aşağılama..vb şeklinde yansıyabilir. Bu tür davranışların öğrenci üzerindeki etkileri ise şunlar olabilir; öğretmen-öğrenci ilişkilerinin zedelenmesi, çocuğun fiziksel ve psikolojik zarar görmesi -ki Taylor ve Maurer fiziksel cezanın neden olabileceği yaralanmaları belgeleriyle şu şeklide belirtmektedir; Başa alınan darbelerden; kanama, beyin travması, kafa tasında çatlak.. sarsılmada; omur kırıklıkları, beyinde hasar... karın ve göğüs bölgesine alınan darbelerden; solunum yetersizliği, kaburgalarda kırıklıklar, iç organlarda aşırı kanama, karaciğerde yırtılma, dalak patlaması.. dayaklardan; kırıklar, eklem çıkıkları, çürükler, bacaklarda felç..- saldırganlık, model alma yoluyla olumsuz davranışları öğrenme, isyan etme, intikam alma, yalan söyleme, okuldan kaçma, depresyona girme, korkma, güvensizlik hissetme, sürekli onay arama, aşırı yemek yeme, boyun eğme, uyuşturucu kullanma, psikosomatik hastalık belirtileri gösterme. Yine Watson'ın 230 üniversite son sinıf öğrencileriyle yaptığı araştırma sonuçlarına göre çok cezalandırılan çocukların 
ana babalarından nefret ettikleri, sınıf arkadaşlarıyla ilişkilerinin kötü olduğu, daha kavgacı, kaygılı ve mutsuz oldukları sonucuna ulaşmıştır.

Öğrencilerin olumsuz davranışlarının ne kadarı kalıtımla geldiği bilinmez ama çoğunun "denetim” odaklı aile, okul ve çevre ortamında öğrendiği söylenebilir.

Sınıfta istenmeyen davranışların üstesinden gelmek sınıf disiplini ile ilgilidir. Sınıfta, öğrencilere istenilen davranışlar kazandırılmaya ve istenmeyen davranışların üstesinden gelinmeye çalışılmaktadır. Öğretmenler, öğrencilere fiziksel ve psikolojik zarar vermeden disiplin sağlamak istiyorlarsa, varolan disiplin sağlama modellerinden de yararlanarak bir disiplin sistemi oluşturmakla işe başlayabilirler.

Charles'e(1996) göre günümüzde öğretmenlerin sınıfta temel sorunu, her bireyin temel gereksinimlerinin karşılanmasından ziyade, kabul edilebilir sınıf davranışlarını oluşturmaktır. Sınıf davranışlarını oluşturmada yarar sağlayan disiplin modelleri tüm yaştaki öğrencilere, tüm düzeydeki öğretmenlere ve durumlara uygun olmayabilir. Çünkü öğrencilerin geçmiş yaşantıları ile öğretmenlerin kişilikleri, felsefeleri, öğretim yöntemleri, iletişim yöntemleri farklılık göstermektedir. Sonuç olarak da her öğretmen kendi disiplin sistemini oluşturmalıdır. Her öğretmenin kendine özgü disiplin sistemini oluşturması zor bir iş değildir. Öğretmenler, öğrencilerinden olumlu davranmalarını ve öğrenmeye ilgilerini yoğun şekilde vermelerini beklerler. Ancak, böyle ideal gruplarla her zaman öğretmenler karşılaşamayabilirler.

$\mathrm{O}$ halde öğretmenler, dönem boyunca uygulayabilecekleri bir disiplin sistemini önceden oluşturmalıdır. Önceden disiplin sistemi oluşturulmadan, sinıfta rastgele sorunlara yönelik tepkilerde bulunmak etkili olmayabilir. Öğretmen sistemini geliştirirken; kurallar, sonuçlar, pekiştireçler, önleyici teknikler, destekleyici teknikler, düzeltici teknikler, beden dili, öğrenme etkinlikleri, ciddi istenmeyen davranışlı öğrencilere yönelik teknikler gibi ölçütleri kullanabilir.

\section{Disiplin Sistemi Ölçütleri Kurallar}


Aydın, B. / Sosyal Bilimler Araştırmaları Dergisi. 2, (2006): 19-32

Özellikle ilköğretim kademesindeki öğrenciler, sınıfta hangi davranışların yapılacağı hangi davranışların yapılmayacağı konusunda belirsizlik yaşayabilirler. Yaptıkları bir davranışın istenmeyen davranış olduğunu bilmeyebilirler. İstenilen davranışlan tahmin etmelerini beklemek ise yanlış bir beklentidir. O halde yapılması gereken, dönemin ilk derslerinde etkili öğrenmelerin gerçekleşmesine yönelik sınıfta yapılması ve yapılmaması gerekenlerin yani kuralların belirlenmesidir.

Kurallar, tüm disiplin sistemlerinin merkezinde yer alır (Curwin, Richard, 1999). Kuralların oluşturulması, sınıf düzeni, zamanın etkin kullanımı, öğretimin etkililiği ve güvenlik açılarından önemlidir. Sınıf kurallarının etkili olması için; öğrencilerle birlikte belirlenmesi, uygun ifade edilmesi (basit, sade, anlaşılır, gözlenebilir, ölçülebilir olması, olumlu ifadelerle sonlanması, emir niteliği taşımaması vb), az sayıda olması, uygun sunum içermesi (ilköğretim birinci kademede resim ya da şekillerle ifade edilmesi), öğretilmesi, izlenmesi, okul yönetimi ve aile desteğinin alınması gerekmektedir (Okutan, Aksoy ve diğerleri, 2003)

\section{Sonuçlar}

Sınıfta, kuralların oluşturulması yanında, öğrencilerin kurallara uyduklarında veya uymadıklarında neyle karşılaşacakları yani sonuçlar da belirlenmelidir. Dreikurs istenmeyen davranışı mantıklı bir sonucun izlemesi gerektiğini ve bunun cezadan farklı olduğunu belirtmektedir (Charles, 1996)

sonuçlar-ceza karşılaştırması;

sonuçlar ile ceza birbirine benzer görünmesine rağmen aralarında önemli farklar vardır. Farklar şu şekilde belirtilebilir; ceza öncelikle intikam içeriklidir. Amacı, istenmeyen davranışın karşılığını ödettirmektir. Temel motive edici faktör korkudur. Ceza verildiğinde gerilime neden olur. Cezalar kısa dönemli istenmeyen davranışı durdurur, uzun dönemde davranışı değiştirmede etkisizdir. Öğrenci, istenmeyen davranış yapmak istediğinde yakalanmamanın önemli olduğunu öğrenir. Sonuçlar ise kuralla doğrudan ilişkilidir ve öğrencinin kabul edilebilir davranışı öğrenmelerine yardım eder. Sonuçların amacı, öğrencilere davranışlarının olumlu ve olumsuz etkilerini öğretmektir. Sonuçlar, etkili şekilde uygulandığında öğrenciler nasıl uygun 
şekilde davranacaklarını ve kurallara uyacaklarını öğrenebilirler. Aşağıda sonuçlar ile cezanın farkını gösteren örnekler sunulmuştur.

Kural: Tüm çöpler çöp kutusuna atılmalı

Sonuç: Yerdeki çöpleri toplamak

Ceza: tüm sınıfın önünde öğretmenden özür dileme

Kural: Testler ve ev ödevleri grup ödevi şeklinde verilmediğinde herkes kendisi yapmalıdır

Sonuç: Gözetim altında test veya ödevi tekrar yapma

Ceza: “diğer öğrencilerin çalışmasını kopya etmeyeceğim” şeklinde 100 defa yazma

Kural: Başka birisi konuştuğu zaman konuşmama. Eğer konuşmak isteniyorsa, konuşmacı sözünü bitirene kadar bekleme

Sonuç: konuşmadan önce beş dakika bekleme

Ceza: dersin sonuna kadar sınıf dışında belirlenen bir yerde oturma

Kural: zil çaldıktan sonra 5 dakika içinde yeride olma.

Sonuç: Gecikmenizden dolayı kaçırdığınız bilgiyi almaktan veya kaçırdığınız çalışmayı tamamlamaktan herkes

ceza: Müdür odasında oturarak tüm dersi izleyememe sonra çalışmayı tamamlama kendisi sorumludur (Curwin, Richard, 1999).

Öğrenciler, kurallara uyduklarında olumlu, uymadıklarında olumsuz sonuçlarla karşılaşacaklarını bilmelidirler. Kurallara uyulmadığında daha önce belirlenen ve hiyerarşik bir yapı izleyen sonuçlar uygulanabilir. Örneğin; öğrenciler kurala uymadıklarında, kurala uymama sıklığı ve sonuç aşağıda gösterilmiştir.

İstenmeyen davranıș $\quad \underline{\text { sonuc }}$

İlk kez tahtaya ismini yazma

İkinci kez okul çıkışında 15 dakika bekleme

Üçüncü kez okul çıkışında 30 dakika bekleme 
Aydın, B. / Sosyal Bilimler Araştırmaları Dergisi. 2, (2006): 19-32

Dördüncü kez

Beşinci okul çıkışında 30 dakika bekletme ve

ailesini çă̆ırma

kez sınıftan çıkarma müdür veya

yardımcısına gönderme (Tauber, 1999).

\section{Pekiştireçler}

Öğrencilerin kendi davranışlarını kontrol etmelerine yardım eden yollardan biri pekiştireçlerdir. Pekiştireç teorisi, ödül ve ceza çeşitlerinden herhangi birini kullanan disiplin sistemlerinin temelini oluşturmaktadır. Günümüzde, psikoloji, davranış, sosyal ve bilişsel psikoloji, pekiştireçlerin olumlu davranışı sürdürme ve güçlendirme, olumsuz davranışı azaltmak için bir araç olduğu konusunda birleşmişlerdir (McLeod, 2003). Skinner'in disiplin sağlama modelinde pekiştireçler önemli yer tutmaktadır. Skinner, öğretmenin öncelikle sınıfta istenen bir davranışı gözlemlemelerini, sonra bu davranışa pekiştireç verilmesini önerir. Dikkat edilirse öğretmen sınıfta istenmeyen davranışı görmezden gelir. İstenen davranışı gösteren öğrenciler üzerine odaklanır. Bunun iki yararı vardır. Birincisi; pekiştireç alan öğrenci olumlu davranışını devam ettirir. İkincisi ise diğer öğrenciler pekiştireç alan öğrencinin davranışını model alarak öğrenirler. Öğretmen, pekiştireç olarak; sosyal (sözelsözsüz), grafik (not, yıldız, mutlu yüz..vb), etkinlik, somut ve dönüştürülebilir sembol pekiştireçlerini öğrencinin yaşına ve özelliğine göre verebilir (Charles, 1996)

\section{Önleyici teknikler}

Önleyici teknikler, sorun ortaya çıkmadan önce önlem almayı gerektiren tekniklerdir. Sınıf kurallarının oluşturulması önlemsel bir teknik olarak düşünülebilir. Hangi davranışların kabul edilebilir hangi davranışların kabul edilemez olduğunu bilmek davranışın gösterilmesi veya gösterilmemesi açısından önemlidir. Charles ( 1996) sınıfta istenmeyen davranışları önlemenin yollarından birinin faydalı ve eğlenceli bir program hazırlamak olduğunu ifade eder. Yıldız (2006) tarafından yapılan araştırmada öğretmenler, istenmeyen davranışları önlemek için; sorumluluk verme, öğrencilerle olumlu iletişim kurma, aile ile işbirliği, motivasyon sağlama, ön sırada oturtma, derse katılımını 
sağlama, değerli olduğunu hissettirme, sınıfta dolaşma, toplantı düzenleme, fiziki durumu düzenleme, etkinlik yaptırma gibi yaklaşımları kullanmaktadırlar.

\section{Destekleyici teknikler}

İstenmeyen davranışın ilk ortaya çıkmaya başladığında destekleyici teknikler kullanılabilir. Disiplinin bu yönü, öğrencilerin kendi kontrollerini sağlamalarına yardım eder. Öğretmenler, destekleyici teknikler olarak şunları kullanabilir.

Desteğe gereksinim duyan öğrenciye yönelik işaretler kullanma. Öğrencilerin bakışlarını yakalamayı öğrenme. Başla onaylama, kaş çatma, onları yönlendiren el işaretleri kullanma.

İşaretler etkisiz olduğunda öğrencinin yanına gitme.

Öğrencinin çalışmasına ilgi gösterme.

Üstesinden gelinmesi güç olan çalışmaları tekrar yapılandırma ve yardım etme.

Yorucu derslere mizahı katma.

İlgi çekici nesneleri ortadan kaldırma.

Uygun şekilde, uygun zamanda doğru davranışı onaylama. Bu, başla onaylama, gülümseme, ve "teşekkürler", "iyi”, “devam et”, gibi kelimelerle yapılabilir (Charles, 1996).

\section{Düzeltici teknikler}

Önleyici ve destekleyici teknikler en etkili şekilde kullanılsa bile istenmeyen davranışlar tümüyle ortadan kaldırılamayabilir. Öğrenciler istenmeyen davranışta bulunduktan sonra onu düzeltmek için bazı tekniklere gereksinim vardır. Bu teknikleri kullanırken öğrencilere göz dağı vermemeye ve güç mücadelesine girmemeye dikkat edilmelidir. Düzeltici teknikler olarak aşağıdaki tepkiler önerilir.

İstenmeyen davranışı durdurma. Eğer davranış kurala uymama ile sonuçlanırsa -kavga etme, yüksek sesle küfretme gibi- hemen üstesinden sözel ifadeler kullanılarak gelinmelidir.

İstenmeyen davranış meydana geldiğinde uygun sonuca başvurma. Sınıf kural ve sonuçlarını enine boyuna tartıştığınızda öğrenciler bu süreci anlarlar. 
Aydın, B. / Sosyal Bilimler Araştırmaları Dergisi. 2, (2006): 19-32

Olumlu talimatlarla istenmeyen davranışı tekrar yönlendirme. Davranışlarıyla ilgili öğrencilerle konuşulabilir. Öğretmen, başkalarını rahatsız etmemeleri konusunda onlara nasıl yardımcı olabileceğini sorabilir.

Sonuca uymayı reddeden öğrencilerden, uymaya karar verinceye kadar okul içinde belirlenen bir yerde durmaları istenebilir (Charles,1996).

\section{Beden dili}

Sınıfta beden dili iki boyutta düşünülebilir. 1. Öğretmenin beden dili 2 . Öğrencinin beden dili. Öğretmen beden dilini temel rolleri olan öğretimi gerçekleştirmede ve disiplini sağlamada kullanabilir. Öğrencinin beden dili mesajları, davranışlarının öğrenmeye mi, yoksa istenmeyen davranışlara mı yönelik olduğu anlamları taşıyabilir (Aydın 2002) Jones beden dilinin; göz iletişimi, fiziksel yakınlık, beden duruşu, yüz ifadeleri ve jestlerden oluştuğunu belirtmektedir. Jones'e göre öğretmen disiplini sağlamada sözlü müdahaleden önce beden dilini kullanmalıdır. Çünkü sözlü müdahaleler zaman kaybına yol açmaktadır. Öğretmen öğrenci ile göz iletişimi kurarak, yanına giderek, yüz ifadelerini kullanarak disiplin sorunlarının üstesinden gelebilir (Charles, 1996)

\section{Öğrenme etkinlikleri}

Munn ve diğerlerine göre (1992) etkili sınıf disiplini, öğrenmenin gerçekleşmesi için gerekmektedir. Öğretmenin konu hakkındaki bilgisi, ifadelerinin açıklı̆ı ve niteliği, öğrencilerin bildikleri ile bunlanı karşılaştırmaları etkili öğrenme üzerinde önemli derecede etkilidir. Sınıfta disiplin olmadığında öğrenme ciddi şekilde engellenir. Etkili disiplin, etkili öğrenmenin yeterli değilse bile gerekli bir ön şartıdır.

Aydın (2001)'ın yaptığı araştırmada öğrenciler, kendilerini disiplin sorunlarına yönelten faktörlerden birinin dersten sıkılma olduğunu belirtmişlerdir. Öğrenciler, sıklıma nedenlerini; öğretmenin sadece konuyu yazdırması, okuması, okutturması gibi öğrenme etkinliklerinden kaynaklandığını ifade etmişlerdir.

Kounin, disiplin sağlamada başarılı öğretmenlerin derslerini; sesli etkinlikler, sessiz etkinlikler, oturarak yapılan etkinlikler, tartışma soruları sorma gibi farklı etkinliklerle işlediklerini belirtmektedir. Ayrıca öğretmen 
derslerinde öğrencilerin dikkatlerinin sürekliliğini sağlayabilmeleri için bazı ilgi çekici cümleler kurabilir. Örneğin; öğretmenin "bugün sizinle bir sırrımı paylaşacağım" demesi, sınıfın kapısına "bugün coğrafi keşiflerin hiç bilinmeyen yönlerinden bahsedeceğim" yazılı bir karton asması öğrencilerin dikkatlerini çekecektir (Charles, 1996).

\section{Ciddi sorunlu öğrencilere yönelik teknikler}

Curwin ve Mendler'e göre, bir sınıfta öğrencilerin yaklaşık yüzde 5'i olan bu öğrenciler, özellikle öğretimi engellerler, öğrenmeye zarar verirler, öğrenmek için çaba sarf etmezler, öğretmenin istek ve emirlerini önemsemezler, başarısız olup olmamaları, öğretmeni sıkıp sıkmamaları, dersi bölüp bölmemelerinden endişelenmezler ve öğretmene hayatı çekilmez hale getirirler. $\mathrm{Bu}$ şekilde davrandıkları için okulda akademik başarıları düşüktür. Geleneksel disiplin metotları ciddi sorunlu olan öğrenciler üzerinde etkisizdir. Bu öğrenciler azarlanmaya, alaya alınmaya, fazladan yazma ödevleri vermeye, tahtaya isimlerinin yazılmasına, müdür odasına gönderilmeye bağışıklık kazanmışlardır.

Curwin ve Mendler böyle öğrencilere akademik başarı konusunda ümitlerini tekrar kazanmalarına yardımcı olunduğunda davranışlarının düzelebileceğini iddia etmektedirler. Öğretmenler, bu öğrencilere başarı ümitlerini, çok cazip öğrenmeler sağlayarak ve başarılı olabileceği ortamlar oluşturarak kazandırabilirler. Diğer bir yol ise onlara değer vermektir (Charles, 1996)

Disiplin sisteminin oluşturulmasına yönelik bu ölçütler değişmez nitelik taşımamaktadır. Öğretmenler, kendilerinin, öğrencilerin ve şartların özelliklerine göre yeni ölçütler belirleyebilir veya bu ölçütlerden bazılarını çıkarabilirler.

Disiplin sisteminin gelişimi ve yürütülmesinde öğrenciler işin içine katılmalı, aile ve yöneticilere plan iletilmelidir. Plan uygulanırken öğretmenin olumsuz tutumlar sergilememsi de önem taşımaktadır (Charles,1996). Aşağıda, bir örnek olması açısından, Sund'un 3. sınıfta kullanılmak üzere hazırladığı bir model sunulmuştur. 
Sund'un 3. sinıfa yönelik disiplin sistemi modeli;

Gereksinimlerim;

1. Sınıfın düzenli görünümü: sınıf düzeni, materyallerin düzgün şekilde yerleştirilmesi

2. Yapı ve işlemler: esnek bir program oluşturma ve gereksinim duyulduğunda uygulama

3. Geçişler: etkinlikler arasında zaman kaybetmeden düzgün geçişler.

4. Dikkat: öğrencilerin dikkatini, yönergelere ve öğretimsel etkinliklere çekme

5. duruma göre uygun davranışlar: öğretim süresince sessiz dikkat, grup etkinlikleri süresince uygun etkileşim.

Hoşlandıklarım;

1. Benim ve öğrencilerimin istekliliğgi

2. Kendini kontrolü, karşılıklı yardımlaşmayı ve sorumluluk almayı netice veren olumlu, rahat sinif ortamı.

Hoşlanmadıklarım:

1. Konuşma, öğretmene ve diğer yetişkinlere veya sınıf arkadaşlarına dikkati vermeme

2. Aşırı gürültü, yüksek ses, uygunsuz konuşma, gülme

3. Zihni başka yere verme, oyuncaklar, gereksiz hareket, gereksiz dolaşma, sıkıntı verme

4. Eşyalara zarar verme, yanlış kullanma, israf etme, öğretim materyallerine zarar verme

5. Nezaketsiz davranış: sınıfta başkalarına sözel/fiziksel zarar verme.

6. Kaba davranış, alay etme, küçümseyici söz, kötü tavırlar

7. Başkasını şikayet etme

Sinif Kuralları

Öğrencilerle uzlaşmaya varacağım sınıf kuralları;

1. Her zaman diğerlerine saygılı olma. Kibar konuşma, yardımcı olma, başkalarını sıkmama

2. Çalışmanın en iyisini yapma: yapılabildiği kadar çok çalışma, gurur duyulabilecek düzenli çalışma yapma, boşa zaman harcamama 
3. Sınıfta sessiz konuşma; sınıf tartışmaları süresince çalışmaya uygun ses kullanma, işbirlikçi çalışma grup içinde sessiz konuşma,

4. İzin ve yardım isterken işaretleri kullanma; (yardım isteme, dolaşma, tuvalete gitmek için işaret sistemini ben açıklayacağım)

5. Okulun ilk gününde öğrencilerle enine boyuna bu kuralları tartı̧̧ırım.

6. Onların düşünce ve önerilerini alırım.

7. Kural ve rutinlerde anlaşmaya vardıktan sonra öğrencilere ipuçları, kuralları içselleştirmelerine yardım eden diğer yardımları vermeye devam ederim.

Olumlu sonuçlar; öğrenciler kurallara uyarken, aşağıdaki olumlu sonuçlarla karşılaşacaklarını bilirler.

1. Olumlu sözel geribildirim,

2. Olumlu sözel olmayan geribildirim (gülümseme, göz kırpma, başla onaylama, el veya bir nesneyle hafifçe bir yere vurma,

3. Gerektiğinde somut ve ayrıcalıklı ödül (stikır, not veya hoşlanılan etkinlikler)

4. Ailelere olumlu rapor (telefon veya notla)

Olumsuz sonuçlar; öğrenciler kurallara uymadıklarında aşağıdaki olumsuz sonuçlarla karşılaşacaklarını bilirler.

1. Hayal kırıklığ 1 ve şaşkınlık içeren ifadelerle sert bir bakış,

2. Onaylanmadığını gösteren genel eleştiriler: "gürültü duyuyorum", "bazıları dinlemiyor",

3. Doğrudan olumsuz sözel geribildirim: "Gordon, işaretleri kullanmadın, lütfen işaretleri kullan",

4. Ailelere olumsuz raporlar: not, telefon etme, okul toplantıları

5. Sınıf içinde ayırma: öğretmenin gözetiminde gruptan öğrenciyi ayırma

6. Öğrenciyi müdüre veya danışmana gönderme ve sınıftan uzaklaştırma

Disiplin ölçütleri: önleyici disiplin ölçütlerim;

Sınıfta davranış sorunlarının meydana gelmesini en aza indirmek için aşağıdaki adımları atarım.

1. Sınıf kurallarını oluşturma ve sorumluluk almaya öğrencileri dahil etme. Görüşmelerde şöyle sorular sorarım. "herkes aynı zamanda 
Aydın, B. / Sosyal Bilimler Araştırmaları Dergisi. 2, (2006): 19-32

konuşmaya çalıştığı zaman ne olacağını düşünürsünüz”, "diğer insanların sizinle nasıl konuşmasından hoşlanırsınız"

2. Ailelerle şu şekilde iletişime geçme;

a. Beklentiler ve disiplin sisteminin özellikleriyle ilgili mektup gönderme

b. Ailelerle, kısa olumlu telefon görüşmeleri yapma

c. Çocuklardan evlerine başarılı çalışmaları ve davranışlarıyla ilgili notlar gönderme

3. Sınıf ortamını, 1sı, 1şık, rahatlık, sınıf içinde etkili hareketi sağlayan trafik akışı için en iyi şekilde düzenleme.

4. Olumlu tavırlar, saygı ve sorumlulukla ilgili toplantılar yapın, önemini vurgulayın, model olma.

5. Fiziksel hareket, şarkı söyleme, etkileşim ve fırsatlarını içeren farklı aktif bir program oluşturma.

6. Yapı ve rutinlerle ilgili bağll1ı, benimseme ve güvenlik duygusunu oluşturma.

Destekleyici disiplin ölçütlerim: öğrencilerin, kendilerini kontrollerini sağlamasına yardım etmek için aşağıdaki destekleyici ölçütleri kullanırım.

1. Göz iletişimi, yüz ifadeleri

2. Öğrencinin yanına doğru gitme

3. Sinıf kurallarını hatırlatma

4. Öğrencinin çalışmalarına ilgi gösterme

5. İlgiyi artırma ve endişeyi azaltmak için gerekirse etkinlik ve rutinleri değiștirme

Düzeltici disiplin ölçütlerim: öğrencilerim istenmeyen şekilde davrandıkları zaman aşağıdaki düzeltici ölçütleri kullanırım.

1. İstenmeyen davranışı eleştirme: "konuşmayı duyuyorum. Ondan hoşlanmıyorum. Herkes dinliyor olmalı"

2. Vurgulu emir: "hemen durdur şunu"

3. Gruptan öğrenciyi ayırma.

4. Öğrenciyi müdür veya danışman odasına gönderme

5. Aile ile telefonla iletişim kurma. 
Aydın, B. / Sosyal Bilimler Araştırmaları Dergisi. 2, (2006): 19-32

Olumlu bir sınıf iklimini sürdürmede yöntemlerim:daha olumlu duyguların, daha çok eğlenmenin, hem kendi kontrolümü hem de öğrencilerimin kendini kontrollerini gerçekleşmelerinin olumlu bir iklimle olabileceğini anladım. Böyle bir iklimi devam ettirebileceğim şeylerden bazıları aşağıdadır.

1. İyi bir eğitim verilen bir birey olarak her çocuğa saygı duyma,

2. Her çocukta olumlu veya hoşa giden nitelikler arama

3. Uygun davranış, verimli çalışma, çaba ve gelişimi onaylama

4. Öğrencileri daha iyi tanımanın zaman alması

5. Mümkün olduğu kadar çok sözel olmayan olumlu tepkiler- göz kırpma, başla onaylama, gülümseme- verme

6. Her gün öğrenci duygularını belirlemenin zaman alması

7. Öğrencilerin kendi yeteneklerini belirten yöntemleri öğrencilerle konuşma-örn; tamam, sonraki adımda ne yapacağını biliyorsun"

8. Sorun olan ancak öğrencilerin başarabileceği ilgi çeken eğlenceli etkinlikleri oluşturma

9. Her gün, yarının mutlu ve verimli olması umudu ve içten söylenen iyi dileklerle dersi bitirme.

\section{Sonuç:}

Öğretmenler, sınıflarında disiplin sorunlarının üstesinden gelmek istiyorlarsa öncelikle bir disiplin sistemi oluşturarak işe başlayabilirler. $\mathrm{Bu}$ disiplin planında yer alacak ölçütler kendi sınıfına göre farklılık gösterebilir. Oluşturulan bir disiplin sistemi öğrencilere duygusal, sosyal yönlerden daha rahat hissedebilecekleri bir öğrenme ortamı sunabilir.

\section{KAYNAKÇA}

Aydın, B. (2002). İlköğretim Okullarında Sınıf Disiplinin Sağlanması. Abant İzzet Baysal Üniversitesi Sosyal Bilimler Enstitüsü, Yayınlanmamış Doktora Tezi. Bolu. 
Aydın, B. (2002) Sınıf Disiplini ve Sınıfta Beden Dili. XI. Eğitim Bilimleri Kongresi. Kıbrıs Yakın Doğu Üniversitesi Atatürk Eğitim Fakültesi. Lefkoşa.

Charles, C. M. (1996). Building Classroom Discipline. New York: Longman.

Curwin, R. (1999). Discipline with Dignity.Alexandria, VA, Association for Supervision \& Curriculum Development. USA

Gordon, T. (2000). Çocukta Dış Disiplin mi? İç Disiplin mi?.(çeviren: Emel Aksay). Sistem yayıncılık. İstanbul.

McLeod, J. (2003). Key Elements of Classroom Management : Managing Time and Space, Student Behavior, and Instructional Strategies. Alexandria, VA, Association for Supervision \& Curriculum Development, USA.

Munn P., Johnstone M., Chalmers V. (1992) Effective Discipline in Primary Schools and Classrooms. Paul Chapman Publihing. London

Okutan, A. ve diğerleri. (2003). Sınıf Yönetimi. Pegem yayınları. Ankara.

Tauber, R. T. (1999). Classroom Management : Sound Theory \& Effective Practice. Westport, CT,: Greenwood Publishing Group, Incorporated. USA.

Yıldız, B. (2006). Sınıf Öğretmenlerinin İstenmeyen Davranışlarda Kullandıkları Önleyici Yaklaşımlar ve Bu Yaklaşımların Etkililiğine İlişkin Öğrenci Görüşleri. Abant İzzet Baysal Üniversitesi Sosyal Bilimler Enstitüsü, Yayınlanmamış yüksek lisans tezi Tezi. Bolu 